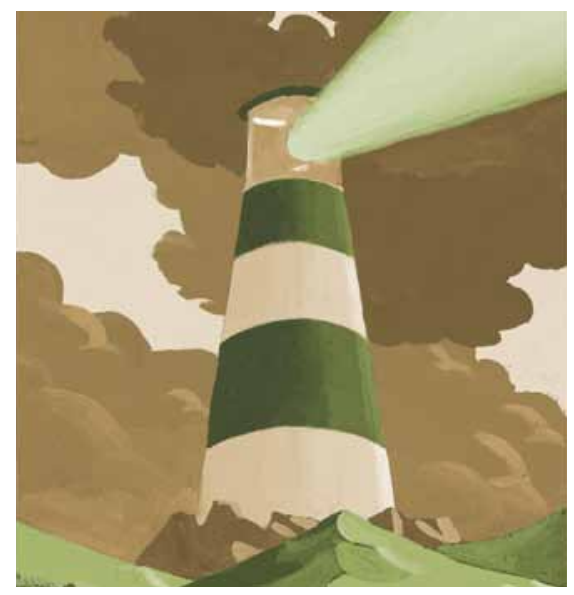

$\mathrm{T}$ he world economy finds itself in one of the most adverse economic climates. It started as a downturn and then worsened into a deep recession. With organisations everywhere being buffeted by the economic storm, the question may be asked: What are South African companies doing to keep afloat and steer towards sustainability?

The authors, who work as a multidisciplinary group of consultants, set out to obtain the South African perspective by interviewing 17 companies operating in different sectors and industries. The aim was to find out what strategies they are using to survive the downturn and how they are preparing for a likely upswing later.

\section{Companies' navigational strategies}

All the companies that participated in the study had been experiencing the impact of the downturn and were reviewing their current operations, especially in terms of their structures, processes and people, and the core purpose of the business. They also realised that an appropriate reaction to the downturn would ease their ability to bounce back when the upswing comes. The strategies they were employing were seen as vital drivers for their future sustainability. These were largely directed at revitalising organisational capability and building a desired corporate culture.

Five strong themes emerged from these interviews. The first theme was to strive for a developmental climate, while the others highlighted the need for perceptual flexibility, innovation within strategic renewal, an engaging leadership style, and harnessing latent learning opportunities. These fives themes are depicted in the diagram on the right.

\title{
Weathering the economic storm
}

Building an organisation with the buoyancy to withstand turbulent economic cycles is critical to survival and future growth.

by Roger Maitland, Brett Anderson-Terry and Kim Filies

1 Foster a developmental climate

A company that is conducive to development is characterised by low resistance to change and low levels of tension. In such a climate, new events have a positive emotional association and employees generally sense that there are adequate resources to deal with the change.

Respondents pointed out several factors that help to create such a climate, for example, giving employees the freedom to make candid and objective decisions, and motivating and energising employees to achieve common goals. Leaders that establish a positive image of the business help to bring about an optimistic mood among employees. Since people largely rely on connections with others to create emotional stability, the emotional levels of employees, both positive and negative, are contagious. Threats such as a recessionary environment can wreak havoc in the workplace if leaders do not succeed in creating a positive climate.

According to one respondent, the chief economist of a major South African insurance company, South African markets usually react to a global downturn about 17 months after it has hit the First World. South African companies with climates that are open to change and to recognising external challenges will have employees that are more likely to learn from international competitors and find new opportunities at an early stage.

\section{Enable perceptual flexibility}

Perceptual flexibility refers to an environment that is capable of inviting and dealing with multiple perspectives on a situation. Real innovation often comes from entertaining different perspectives and creating opportunities to juxtapose different possibilities. Incremental improvement is innova-

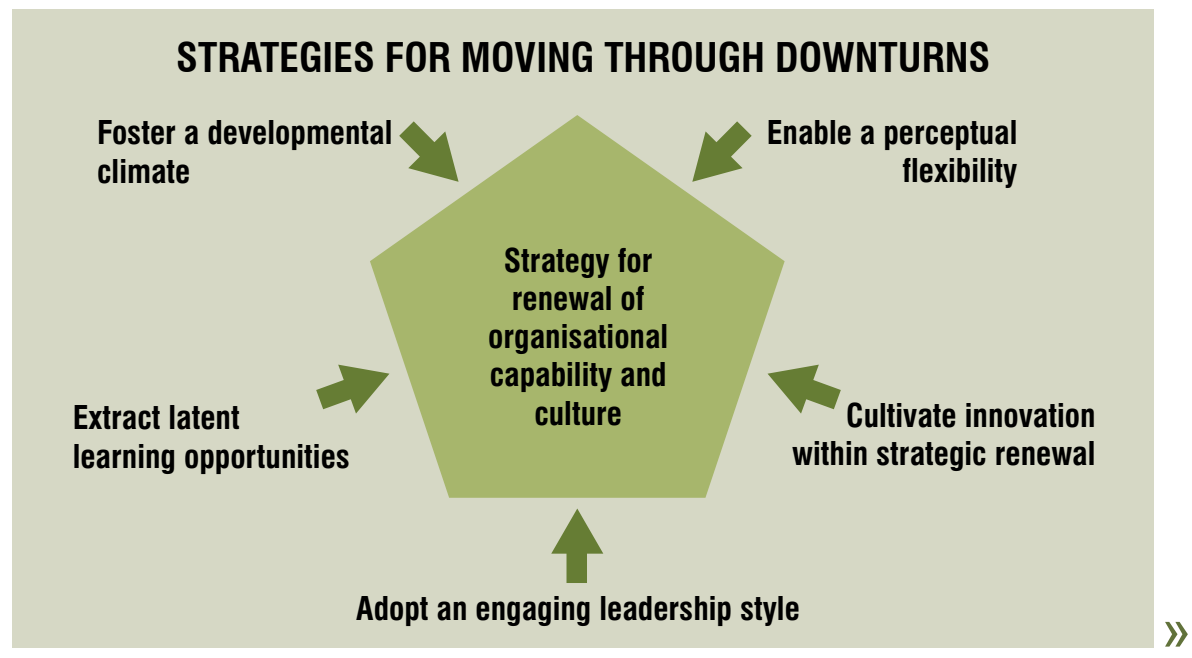


tion's worst enemy. Big steps forward are made when mixtures of ideas from different people, different backgrounds and even different cultures could be viewed side by side.

People should be encouraged to gain insight through researching factors that are internal and external to the organisation. Employees can learn about competitors and their customers, explore how customers' needs and means have changed, and review the present product range and positioning. Gathering data in this way enables divergent thinking, as is often used to stimulate creative thinking in innovation process models. When the level of stimuli in an organisation is raised, the quality of thinking improves.

\section{For continued survival and growth, the rate of learning must be equal to or greater than the rate of change}

Perceptual flexibility enables executives and employees at all levels in the organisation to draw from the richness of multiple approaches to renewal initiatives.

\section{Cultivate innovation within strategic renewal}

The need to stimulate innovation was clearly identified as important by the interviewed companies. Furthermore, it is crucial to bring out-of-the-box thinking to the strategy table. Allowing room for creativity around strategic initiatives could be a valuable option to explore during an economic downturn. Respondents emphasised, however, that the decisions taken should always take into account the impact on productivity and the ability to respond quickly once the upswing begins.

Strategic innovation should be balanced with strategies to increase efficiency. This view echoes past research that shows that paradoxical cognition, where creativity and efficiency goals are held simultaneously, serves to increase innovation. The benefit of entertaining a paradoxical focus is to create an agile organisation, able to respond to immediate market challenges while at the same time discovering new opportunities for growth.

Companies asserted that innovation is not a nice-to-have. Innovation is the only long-term differentiator for businesses and enables them to capitalise on opportunities present in difficult economic times. Still, reaping its rewards demands the integration of innovation into the organisational culture. It is advisable to start instilling a culture of innovation well before the tough times hit.

In a turbulent business climate, it is important to consider the impact of stress. Because prolonged exposure to stress reduces the capacity to innovate, leaders should support staff to manage stress appropriately in order that this capacity is not encumbered in the organisation.

\section{Adopt an engaging leadership style}

It is easy to adopt an autocratic leadership style during a downturn, as this is a natural response to the pressure to perform and be productive. This tendency, which is pervasive during bad economic times, makes companies vulnerable to losing talent because the focus shifts to managing the numbers rather than maintaining performance and staff morale. The key downfall of the authoritarian approach is that it diminishes the organisation's ability to tap into the expertise of personnel and limits dialogue, thus reducing collective intelligence. This inhibits the organisation's ability to adapt when it is most needed.

The majority of respondents highlighted the importance of engaging and inspiring employees, and of involving them in the process of finding solutions to the challenges faced by the company. Moreover, the way in which employees are led and managed during a downturn will have a direct impact on the ability to respond to an upswing. An engaging and inspirational leadership style will aid in the retention of key talent and competencies in the business while maximising the development of employees. During an economic downturn, leadership needs to invest far more energy in buoying up morale and retaining key skills and competencies.

A balance is needed, though. One company indicated that a more centralised approach during a downturn allows a large organisation to respond more quickly in such a situation. This approach could more readily be followed in a general culture of adequate employee engagement. Should the need for centralised decision-making arise, it does not create adverse consequences for talent retention.

\section{Extract latent learning opportunities}

During competitive times it is vital to manage the development of employees beyond what they are learning on the job or possess in terms of functional skills. Companies pointed out the importance of creating learning opportunities during the downturn or recession. But because of the difficult times, the investment in training had to be limited. The trend was rather to optimise learning opportunities within current experiences and leverage internal resources as coaches and mentors in a practical and cost-effective way.

It is important to recognise that for continued survival and growth, the rate of learning must be equal to or greater than the rate of change. Assisting employees to learn organisational skills beyond their current roles can help to prepare for the opportunities that will come with an upswing.

Training and learning should extend beyond job-related skills. Employees also require better coping strategies, and need to learn skills that will build emotional maturity to handle stressful interactions that often happen during these times. If people fail to deal successfully with the stress of an economic downturn, the productivity of the organisation will suffer.

Downturns provide practical learning experience in coping with difficulties. This should be utilised, and the experience should be reflected upon as part of developing the emotional strengths of the staff for future ups and downs.

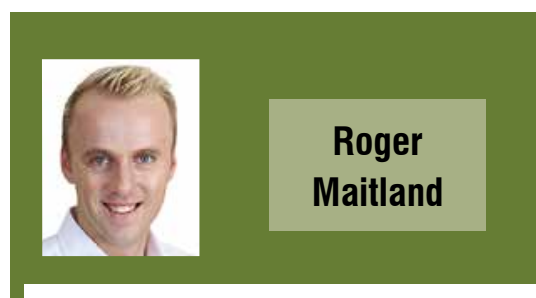

Roger Maitland is an executive coach and a regular lecturer and facilitator on the executive development programmes of USB Executive Development (USB-ED) and the MPhil in Management Coaching programme of the University of Stellenbosch Business School. He and co-authors Brett Anderson-Terry and Kim Filies based this article on their research done for Lifelab. The full report is titled Riding the waves: a research study on South African companies' strategies for survival in a downturn and growth in the upswing (November, 2009). 